\title{
Atividade antimicrobiana de extratos vegetais de especiarias do norte do Brasil
}

\author{
Antimicrobial activity of plant extracts of spices from northern Brazil \\ Actividad antimicrobiana de extractos vegetales de especias del norte de Brasil
}

Recebido: 22/01/2022 | Revisado: 26/01/2022 | Aceito: 02/02/2022 | Publicado: 04/02/2022

\author{
Ananda Emilly de Oliveira Brito \\ ORCID: https://orcid.org/0000-0002-2208-1118 \\ Centro Universitário da Amazônia, Brasil \\ E-mail: anandaemillybrito@gmail.com \\ Carlena Sinara Martins da Silva \\ ORCID: https://orcid.org/0000-0002-1543-8334 \\ Centro Universitário da Amazônia, Brasil \\ E-mail: karlena_sinara@hotmail.com
}

\begin{abstract}
Resumo
A utilização das plantas para fins medicinais é uma prática milenar, nas últimas décadas o uso destas cresceu devido a composição química das espécies vegetais. No Brasil é possível encontrar uma grande diversidade de espécies, em que à sua maioria se encontram na floresta amazônica, uma das maiores fontes de matéria prima, com plantas medicinais com propriedades fitoterápicas. O objetivo deste trabalho foi avaliar extratos vegetais de especiarias da região norte frente as bactérias de Staphylococcus aureus (ATCC 33591) e Escherichia coli (ATCC 25922), avaliando a atividade antimicrobiana, identificando a sua composição química e rendimento dos extratos obtidos a partir da matéria vegetal. As amostras utilizadas foram de chicória (Eryngium foetidum L.), coentro (Coriandrum sativum L.) e jambú (Acmella oleracea (L.) R.K. Jansen), adquiridos no mercado municipal de Santarém, no estado do Pará. Os extratos foram obtidos através do método de extração sólido-líquido, realizando-se a identificação fitoquímica por meio de testes com reagentes específicos. Na pesquisa de antimicrobianos, utilizou-se a difusão em disco. O rendimento dos extratos variaram de acordo com o reagente utilizado. O extrato de chicória apresentou rendimento de $0.76 \%, 46.29 \%, 55.02 \%$ e $9.5 \%$, o coentro $60.5 \%, 48.97 \%, 3.73 \%$ e $18.54 \%$ e o jambú $2.56 \%, 16.66 \%, 5.08 \%$ e $6.92 \%$ para os solventes hexano, clorofórmio, acetato de etila e etanol, respetivamente. O ensaio antimicrobiano frente as cepas $S$. aureus, obtiveram halos de inibição de 10 a $11 \mathrm{~mm}$ para chicória, 7 a $10 \mathrm{~mm}$ para coentro e 8 a 14 mm para jambú. A bactéria E.coli não foi sensível aos extratos testados. Conclui-se que os extratos dos vegetais testados foram eficazes frente ao Staphylococcus aureus, tornando uma alternativa terapêutica para infecções provocadas por esta bactéria.
\end{abstract}

Palavras-chave: Extratos vegetais; Alternativa terapêutica; Antimicrobianos.

\begin{abstract}
The use of plants for medicinal purposes is an ancient practice, in recent decades their use has grown due to the chemical composition of plant species. In Brazil it is possible to find a great diversity of species, most of which are found in the Amazon rainforest, one of the largest sources of raw material, with medicinal plants with phytotherapic properties. The objective of this work was to evaluate plant extracts of spices from the northern region against Staphylococcus aureus (ATCC 33591) and Escherichia coli (ATCC 25922) bacteria, evaluating their antimicrobial activity, identifying their chemical composition and yield of extracts obtained from the vegetable. The samples used were chicory (Eryngium foetidum L.), coriander (Coriandrum sativum L.) and jambú (Acmella oleracea (L.) RK Jansen), acquired in the municipal market of Santarém, in the state of Pará. The extracts were obtained through of the solid-liquid extraction method, carrying out the phytochemical identification through tests with specific reagents. In antimicrobial research, disk diffusion was used. The yield of extracts varied according to the reagent used. The chicory extract showed yields of $0.76 \%, 46.29 \%, 55.02 \%$ and $9.5 \%$, coriander $60.5 \%, 48.97 \%, 3.73 \%$ and $18.54 \%$ and jambu $2.56 \%, 16.66 \%, 5.08 \%$ and $6.92 \%$ for hexane solvents. chloroform, ethyl acetate and ethanol, respectively. The antimicrobial assay against $S$. aureus strains obtained inhibition halos of 10 to $11 \mathrm{~mm}$ for chicory, 7 to $10 \mathrm{~mm}$ for coriander and 8 to $14 \mathrm{~mm}$ for jambú. The E.coli bacterium was not sensitive to the tested extracts. It is concluded that the tested plant extracts were effective against Staphylococcus aureus, making it a therapeutic alternative for infections caused by this bacterium.
\end{abstract}

Keywords: Plant extracts; Therapeutic alternative; Antimicrobials.

\section{Resumen}

El uso de las plantas con fines medicinales es una práctica milenaria, en las últimas décadas su uso ha crecido debido a la composición química de las especies vegetales. En Brasil es posible encontrar una gran diversidad de especies, la mayoría de las cuales se encuentran en la selva amazónica, una de las mayores fuentes de materia prima, con plantas 
medicinales con propiedades fitoterapéuticas. El objetivo de este trabajo fue evaluar extractos vegetales de especias de la región norte frente a las bacterias Staphylococcus aureus (ATCC 33591) y Escherichia coli (ATCC 25922), evaluando su actividad antimicrobiana, identificando su composición química y rendimiento de extractos obtenidos del vegetal. Las muestras utilizadas fueron achicoria (Eryngium foetidum L.), cilantro (Coriandrum sativum L.) y jambú (Acmella oleracea (L.) RK Jansen), adquiridas en el mercado municipal de Santarém, en el estado de Pará. Los extractos fueron obtenidos a través del método de extracción sólido-líquido, realizando la identificación fitoquímica mediante pruebas con reactivos específicos. En la investigación antimicrobiana, se utilizó la difusión en disco. El rendimiento de los extractos varió según el reactivo utilizado. El extracto de achicoria mostró rendimientos de $0.76 \%$, $46.29 \%, 55.02 \%$ y $9.5 \%$, cilantro $60.5 \%, 48.97 \%, 3.73 \%$ y $18.54 \%$ y jambu $2.56 \%, 16.66 \%, 5.08 \%$ y $6.92 \%$ para solventes hexano, cloroformo, acetato de etilo y etanol, respectivamente. El ensayo antimicrobiano contra cepas de $S$. aureus obtuvo halos de inhibición de 10 a $11 \mathrm{~mm}$ para achicoria, 7 a $10 \mathrm{~mm}$ para cilantro y 8 a $14 \mathrm{~mm}$ para jambú. La bacteria E.coli no fue sensible a los extractos probados. Se concluye que los extractos de plantas probados fueron efectivos contra Staphylococcus aureus, por lo que es una alternativa terapéutica para las infecciones causadas por esta bacteria.

Palabras clave: Extractos de plantas; Alternativa terapéutica; Antimicrobianos.

\section{Introdução}

A utilização de plantas e extratos vegetais nas Américas é uma prática que ocorre há milhares de anos, os registros arqueológicos apontam que os ameríndios já usavam algumas espécies vegetais para auxiliar na cura de doenças (Brandão, 2017), sendo um conhecimento transmitido de geração em geração, de forma empírica (Magalhães et al., 2015). O uso desses vegetais tem despertado grande interesse devido à sua composição química, e as substâncias deles extraídas têm sido aplicadas na alimentação ou para benefício da saúde (Silva et al., 2010; Cardoso et al., 2021).

No Brasil a diversidade de espécies vegetais corresponde a 13\% da riqueza mundial (Stehmann, 2017). Com relação a gastronomia, cada região se revela com características bem particulares, onde a mistura de ingredientes é definida por gostos culturais. A região norte é um exemplo, onde a influência indígena se divide entre plantas e animais amazônicos, com elaboração de pratos com diversos temperos, tais como a chicória, coentro e jambu (Corrêa et al.,2016; Cano, 2021).

A chicória (Eryngium foetidum L.) é uma hortaliça muito apreciada na medicina popular e culinária da região amazônica (Batista et al., 2016). Originária da Índia, também se destaca por possuir importantes fontes de vitamina A, C, D, complexo B e sais minerais (Frazão et al., 2013; Rodrigues et al., 2021). Suas propriedades medicinais permitem que seja usada como diurético, antipirético, antídoto (Silva et al., 2017).

O coentro (Coriandrum sativum L.) é outro exemplo, uma das especiarias mais consumidas nas regiões do Brasil, prinicipalmente no Norte e Nordeste, sendo muito apreciado em diversos pratos típicos (Pereira et al., 2011). Além disso apresenta propriedades medicinais como ação lipolítica, diurética, antiinflamatória, antimicrobiana, antioxidante, anticancerígena, antidiabética, antimutagênica (Junior et al., 2014).

O jambú (Acmella oleracea (L.) R.K. Jansen), por sua vez, pertence à família Asteraceae, espécie nativa da Amazônia, também é uma hortaliça muito consumida na região norte, principalmente no estado do Pará (Borges et al., 2013). Na medicina natural, é utilizada devido as suas propriedades, anestésica, estimulante e antiinflamatória (Favoreto et al., 2010).

Diante do exposto, o objetivo do presente trabalho foi de avaliar o extrato vegetal de especiarias da região Norte frente as bactérias de Staphylococcus aureus e Escherichia Coli, identificando a atividade antimicrobiana e analisando a sua composição química e rendimento dos extratos obtidos a partir da matéria vegetal.

\section{Metodologia}

\subsection{Local e amostragem}

Para a realização do estudo foram obtidas especiarias utilizadas na culinária local, entre elas a chicória (Cichorium intybus L.), o jambú (Acmella oleracea (L.) R.K. Jansen) e o coentro (Coriandrum sativum L.). As plantas foram adquiridas no 
mercado municipal de Santarém, estado do Pará, no período de junho de 2019.

\subsection{Preparo da matéria vegetal}

Para a realização das extrações, foi usado $1 \mathrm{~kg}$ do material vegetal fresco, os ensaios foram realizados nas espécies adquiridas, foram levadas para o laboratório do Centro Universitário da Amazônia, onde foram lavadas com água corrente, colocadas em sacos de papel e mantidas na estufa a $45^{\circ} \mathrm{C}$ por 48 horas, logo após foram trituradas para a extração (Junior et al., 2014).

\subsection{Obtenção de extrato vegetal}

Para a realização do experimento, o material vegetal foi submetido ao processo de extração por esgotamento no qual foi utilizado quatro solventes com polaridade distintas (hexano, clorofórmio, acetato de etila e etanol) na proporção de 1:10 (vegetal/solvente), cada solvente esteve em contanto com o material vegetal por 3 dias, e em seguida foi filtrado, os extratos foram submetidos ao rotaevaporador modelo QUIMIS sendo refrigerados de 2 a $8^{\circ} \mathrm{C}$ até o momento das análises (Simonetti, 2015). Obtido os extratos brutos, foram ressuspendidos em água destilada estéril contendo tensoativo (Tween 80) para facilitar a dissolução, foram utilizado $100 \mathrm{mg}$ de extrato vegetal para 1,0 mL de água destilada, o volume total do extrato concentrado obtido (aproximadamente 5,0 mL), foram feitas diluições em água destilada estéril de 1:1;1:2;1:4 e 1:5 (Carvalho et al., 2014).

\subsection{Rendimento do extrato vegetal}

O rendimento do extrato vegetal foi calculado de acordo com a equação abaixo.

$$
\mathrm{Re}=(\text { Pextrato } \backslash \text { Ppartebot }) \text { X100 }
$$

Sendo:

Re: rendimento do extrato (\%)

P extrato: o peso do extrato após raspagem

P partebot: peso do pó utilizado inicialmente (na preparação do extrato hidroalcoolico) (Antunes et al., 2015).

\subsection{Análises fitoquímica}

Os extratos vegetais foram submetidos a uma série de reações de caracterização fitoquímica para detecção da presença de metabólitos secundários como os compostos antraquinonas, taninos, cumarinas, alcalóides e saponinas (Lôbo et al., 2010).

\subsubsection{Testes para Saponinas}

O teste foi realizado por meio de agitação, que consistiu em colocar $1 \mathrm{~g}$ do material vegetal em 10,0 mL de água destilada estéril, a solução foi aquecida por 2 minutos, logo após foi filtrada e transferida para um tubo de ensaio onde então foram agitados até formar espuma, os resultados positivos foram apresentados pela formação de uma espuma persistente por mais que 15 minutos.

Para o teste de hemólise foram pesadas $6 \mathrm{~g}$ de gelatina e dissolvidas em solução fisiológica a $60^{\circ} \mathrm{C}$, foi adicionada a uma placa de petri $5,0 \mathrm{~mL}$ de gelatina aquecida entre 30 e $40^{\circ} \mathrm{C}, 0,2 \mathrm{~mL}$ de sangue com anticoagulante e um fragmento do material vegetal no centro da placa, e foi transferido para o refrigerador por 30 minutos.

Para o índice de espuma foi colocado $0,1 \mathrm{~g}$ do material vegetal em $100 \mathrm{~mL}$ de água destilada, aquecida por 5 minutos e filtrada, em seguida foi determinado o pH da solução, e adicionada mais água destilada até completar $100 \mathrm{~mL}$, foi montado uma bateria de 10 tubos de ensaio iguais, a primeira marcação foi realizada em $10,0 \mathrm{~mL}$ e a segunda 1 centímetro acima da primeira, em seguida os tubos foram agitados por 15 segundos e deixados em repouso por 15 minuto, os resultados positivos 
foram apresentados pela formação de uma espuma persistente (Carrera et al., 2014).

\subsubsection{Testes para Taninos}

Foram pesadas $5 \mathrm{~g}$ do material vegetal e adicionadas a $100 \mathrm{~mL}$ de água destilada, em seguida aquecida por 15 minutos, filtrada e então transferida para 2 tubos de ensaio, sendo um deles o padrão. Para o primeiro teste foi utilizado um tubo contendo 2,0 mL da solução (água/extrato vegetal) e adicionadas 2 gotas de HCI diluído e gelatina gota a gota até observar a mudança de cor, no segundo tubo foi adicionado $2,0 \mathrm{~mL}$ da solução (água/extrato vegetal) e 2 a 4 gotas de cloreto férrico (Rodrigues et al., 2017).

\subsubsection{Testes para Cumarinas}

O pó da droga foi aquecida por 10 minutos em um cadinho tampado, o sublimado foi dissolvido em metanol, foram adicionadas 5 gotas em um papel filtro até secar, e em seguida colocados em câmara com luz ultravioleta. Considerou-se resultado positivo quando a reação ficou azul-esverdeada (Sousa et al., 2018).

\subsubsection{Testes para Alcalóides}

Foram pesadas $2 \mathrm{~g}$ do material vegetal e adicionadas a $\mathrm{H}_{2} \mathrm{SO}_{4}$ a $1 \%$, aquecida por 2 minutos, em seguida, filtrado e separado em dois tubos contendo a mesma proporção, um dos tubos foi utilizado para a pesquisa direta, onde foram adicionados 2 a 4 gotas do reagente de Mayer, considerou-se positivo quando foi observado formação de precipitado.

Para a pesquisa confirmatória foram adicionados $\mathrm{NH}_{4} \mathrm{OH}$ e diluída até que o $\mathrm{pH}$ ficasse básico, foi adicionado 7,0 $\mathrm{mL}$ de $\mathrm{CHCl}_{3}$, e realizado a decantação da solução que se apresentou em duas fases, a camada clorofórmica e a camada orgânica que foram separadas em recipientes distintos, a parte orgânica foi dissolvida em 5,0 $\mathrm{mL}$ de $\mathrm{H}_{2} \mathrm{SO}_{4}$ a 5\%, e adicionadas 2 a 4 gotas do reagente de Mayer, considerou-se positivo quando foi observado precipitados no fundo do tubo (Carrera et al., 2014).

\subsubsection{Teste para Antraquinonas}

Para a realização do teste de Borntrager direto foram transferidos fragmentos da droga para tubos de ensaio e adicionados 5,0 mL de $\mathrm{NH}_{4} \mathrm{OH}$ dil, considerou-se positivo quando a coloração ficou rósea ou avermelhada. Para o teste de Borntrager confirmatório foram colocados $1 \mathrm{~g}$ da droga no tudo de ensaio e adicionados $8,0 \mathrm{~mL}$ de EtOH a $25 \%$, foi aquecido por 1 minuto e filtrado para um tubo contendo $4,0 \mathrm{~mL}$ de $\mathrm{H}_{2} \mathrm{SO}_{4}$ a $5 \%$, em seguida foi aquecido levemente e adicionado a 5,0 $\mathrm{mL}$ de $\mathrm{CHCl}_{3}$, esperou-se 3 minutos para o iniciar a decantação, após esse processo foi utilizada a camada orgânica e adicionado $5,0 \mathrm{~mL}$ de $\mathrm{NH}_{4} \mathrm{OH}$ dil. que ficou em repouso, considerou-se positivo quando a coloração ficou rósea ou avermelhada (Sousa et al., 2018).

\subsection{Atividade antimicrobiana}

Para realização do experimento os microrganismos utilizados foram o Staphylococcus aureus (ATCC 33591); e a Escherichia coli (ATCC 25922), cultivadas em meio Ágar Sangue, Ágar Chocolate e Ágar Maccokey, incubadas a $37^{\circ} \mathrm{C}$ por 24 horas (Araújo et al., 2015). A solução salina $0,9 \%$ foi suspensa até que se observasse uma turvação de acordo com a escala de Mc Farland (9x108UFC/mL), as colônias foram inoculadas em placas com Ágar Muller-Hinton para colocação dos discos (Santos et al., 2016).

O teste de difusão em disco é um método simples e qualitativo realizado em meio de cultura sólido (ágar) em placa, em que é empregada a semeadura do microrganismo, e depois dispostos discos de papel filtro em diferentes concentrações do agente antimicrobiano a ser testado, a classificação do microrganismo é resistente ou sensível a partir do halo de inibição 
formado depois da incubação (Leite, 2016). Os extratos vegetais utilizados na pesquisa foram diluídos em diversas concentrações variando de 25\%,50\%,75\% e 100\%, para realização dos testes de sensibilidade o meio de cultura Ágar Mueller-Hinton foi preparado conforme o fabricante, os discos de papel contendo $10 \mu / \mathrm{ml}$, os extratos vegetais foram dispostos na placa, em seguida foram incubados por $37^{\circ} \mathrm{c}$ durante 48 horas (Araújo et al., 2015). Para controle positivo foi utilizado Amoxilina e o controle negativo água destilada (Andrade et al., 2019).

\section{Resultados e Discussão}

\subsection{Triagem fitoquímica dos extratos}

Conforme os dados registrados na Tabela 1, a partir dos testes realizados foram encontrados, nas drogas vegetais, os metabólitos secundários saponinas e alcalóides foram identificados no jambú, e alcalóides e antraquinonas foram encontrados no coentro e na chicória.

Tabela 1. Resultados da triagem fitoquímica dos extratos.

\begin{tabular}{ccccc}
\hline \multirow{2}{*}{ Compostos pesquisados } & Reações & \multicolumn{3}{c}{ Extratos Vegetais } \\
& & Chicória & Coentro & Jambú \\
\hline Identificação de Taninos & Gelatina & $(-)$ & $(-)$ & $(-)$ \\
& Cloreto férrico & $(-)$ & $(-)$ & $(-)$ \\
Identificação de Cumarinas & Fluorescência & $(-)$ & $(-)$ & $(-)$ \\
Identificação de Saponinas & Agitação & $(-)$ & $(-)$ & $(+)$ \\
& Índice de Espuma & $(-)$ & $(-)$ & $(+)$ \\
Identificação de Alcalóides & Reagente Mayer & $(+)$ & $(+)$ & $(+)$ \\
Identificação de & Borntranger Direta & $(+)$ & $(+)$ & $(-)$ \\
Antraquinonas & Borntranger Hidrólise & $(+)$ & $(+)$ & $(-)$ \\
\hline
\end{tabular}

Fonte: Autores (2021).

Os taninos são substâncias responsáveis por dar aos frutos e vegetais características adstringentes devido a sua precipitação de glicoproteínas salivares. Esses compostos são altamente oxidáveis tanto por enzimas quanto por metais levando ao escurecimento das soluções (Fernandes et al., 2019).

As saponinas são compostos gerados pelas plantas com finalidade de neutralizar patógenos e agentes herbívoros (Fernandes et al., 2019). Essas substâncias estão associadas às atividades hemolítica, antiviral, anti-inflamatória e na redução na falha congestiva cardíaca por inibição do e fluxo celular de $\mathrm{Na}^{+}$(Beserra et al., 2014)

As antraquinonas são compostos orgânicos formados por meio da oxidação de fenóis e apresentam coloração amarela cristalina, no Brasil são utilizadas para a fabricação de laxantes (Abreu et al., 2015).

Os alcalóides são substâncias que apresentam marcante efeito sob o sistema nervoso e são utilizados como alucinógenos ou venenos. São caracterizados por uma ampla gama de atividades biológicas e são considerados potencialmente tóxicos (Beserra et al.,2014; Marques et al., 2015).

As cumarinas apresentam atividades anti-neoplásica, efeito narcótico, hemostático, sedativo, espasma lítico, anticoagulante, analgésico, regulador hormonal e vaso dilatador, além de inibidor da carcinogênese (Pereira et al., 2000).

Os ensaios fitoquímicos droga vegetal da chicória, apresentou positivo para alcalóides e antraquinonas e negativo para saponina, cumarina e taninos. Paul et al., (2011), identificou a presença de flavonóides, taninos saponinas em coentros, porém não foram identificados alcalóides. No jambú foram identificados alcalóides e saponinas. Félix-Silva et al., (2021) identificou no jambú coletada no Rio Grande do Norte, Brasil, taninos, alcalóides e saponinas. 
O coentro foi positivo para alcalóides e antraquinonas, já no estudo de Kumar e colaboradores (2014), foram identificados nas raízes de coentro provenientes da Índia, alcalóides, flavonoides, saponinas, terpenos e fenóis.

A biossíntese dos metabólitos secundários é determinada geneticamente, porém as condições fisiológicas e ambientais podem modificar a sua composição química (Gobbo-Neto et al., 2007).

\subsection{Rendimento dos extratos vegetais}

O método de extração utilizado possibilitou obter extratos de diferentes polaridades devido à utilização a diversidade dos solventes. Na Tabela 2 observa-se o rendimento dos extratos, apresentando uma variação entre $0,76 \%$ a 60,5\%.

Tabela 2. Rendimento dos extratos vegetais

\begin{tabular}{cccc}
\hline & Extrato vegetal & & Rendimento (\%) \\
\cline { 1 - 2 } Droga vegetal & Solvente & \\
\hline \multirow{3}{*}{ Chicória } & Hexano & $0,76 \%$ \\
& Clorofórmio & $46,29 \%$ \\
& Acetato de Etila & $55,02 \%$ \\
& Etanol & $9,50 \%$ \\
Coentro & Hexano & $60,5 \%$ \\
& Clorofórmio & $48,97 \%$ \\
& Acetato de Etila & $3,73 \%$ \\
& Etanol & $18,54 \%$ \\
Jambú & Hexano & $2,56 \%$ \\
& Clorofórmio & $16,66 \%$ \\
& Acetato de Etila & $5,08 \%$ \\
& Etanol & $6,92 \%$ \\
\hline
\end{tabular}

Fonte: Autores (2021).

Entre os solventes usados, o clorofórmio apresentou maior rendimento com 46,29\%, 48,97\% e 16,66\% nos extratos a partir das espécies vegetais chicória, coentro e jambú, respectivamente. Os demais extratos apresentarem variações de rendimento, independente do solvente utilizado. Muitos fatores podem influenciar na extração, tais como: técnica de extração, o tipo de matéria vegetal, o tamanho das partículas, o solvente e a concentração utilizada, o tempo e a temperatura de extração (Andreo et al., 2006; Franzen et al., 2018).

No estudo Simonett et al., (2015), no qual se baseou a metodologia de extração deste trabalho o rendimento dos extratos clorofórmicos apresentaram rendimento superior aos hexânicos, acetato de etila e etanólico da espécie de Psidium salutare var.sericeum(Cambess.)Landrum e Eugenia anomala D.Legrand, apenas os extratos etanólicos P. salutare apresentarem rendimento diferente, superior ao clorofórmio $(2,90 \%)$.

\subsection{Análise microbiológica}

Os testes antimicrobianos realizados com os extratos hexânicos, clorofórmicos, acetato de etila e etanólicos foram testados com cepas de S. aureus e E. coli, conforme descrito na Tabela 3. 
Tabela 3. Testes antimicrobianos.

\begin{tabular}{cccc}
\hline & Extrato Vegetal & & \multicolumn{2}{c}{ Microorganismos } \\
& & Staphylococcus aureus & Escherichia coli \\
\cline { 3 - 4 } Matéria vegetal & Solvente & $11 \pm 1^{*}$ & - \\
\hline Chicória & Hexano & - & - \\
& Clorofórmio & - & - \\
& Acetato de Etila & $10 \pm 1,41^{*}$ & - \\
& Etanol & - & - \\
Coentro & Hexano & - & - \\
& Clorofórmio & $8 \pm 0,81^{*}$ & - \\
& Acetato de Etila & - & - \\
& Etanol & $9 \pm 0,57^{*}$ & - \\
Jambú & Hexano & - & - \\
& Clorofórmio & $8 \pm 1 *$ & - \\
& Acetato de Etila & $8 \pm 0,57^{*}$ & - \\
& Etanol &
\end{tabular}

Controle negativo (água) $=0 \mathrm{~mm}$. Controle positivo (amoxilina) $=21 \pm 0,20 \mathrm{~mm}$. *Desvio padrão. Fonte: Autores (2021).

Os extratos hexânicos e etanólicos de chicória em comparação aos extratos estudados, apresentaram maiores halos de inibição (11 e 10 mm, respectivamente) frente a bactérias Staphylococcus aureus. O jambú foi a espécie vegetal que a bactérias S. aureus foi mais sensível em diferentes solventes hexano $(9 \mathrm{~mm})$, acetato de etila $(8 \mathrm{~mm})$ e etanol $(8 \mathrm{~mm})$, apenas o extrato clorofórmio do jambú não apresentou atividade frente a bactéria. Diferente do coentro que apresentou halo de inibição frente a S. aureus apenas no extrato de acetato de etila $(8 \mathrm{~mm})$.

Utilizando extratos da folha de Psidium guajava L., Andrade et al., (2019), em seu estudo observou halo de 9,03 mm frente a bactéria $S$. aureus, resultado próximo encontrado no extrato de hexano do jambú.

No estudo realizado por Souza et al., (2015) com Schinus terebinthifolius, através do método de disco em estufa seca, obteve-se halos de $10 \mathrm{~mm}$ para $S$. aureus, resultado esse semelhante ao extrato etanólico da chicória. Ainda relacionados aos estudos de Souza et al., (2015), os extratos de Salvia rosmarinus e Schinus terebinthifolius apesentaram um halo de inibição de $8 \mathrm{~mm}$ resultados semelhantes aos extratos de etanolícos do jambú, e acetato de etila do coentro e jambú

O extrato hexânico da chicória apresentou um halo de $11 \mathrm{~mm}$ em contração de $100 \%$, nos estudos de Barros et al., (2018) o extrato de Piper tuberculatum JACQ., apresentou um resultado próximo (12 mm) inibição para $S$. aureus em concentração de $500 \mu \mathrm{g} / \mathrm{ml}$.

A atividade antimicrobiana dos extratos vegetais frente a bactéria de $E$. coli não foram eficazes, o que leva a inferir que não é considerada uma alternativa terapêutica para infecções causadas pela está bactéria em questão.

\section{Considerações Finais}

As espécies vegetais utilizadas frequentemente na culinária paraense possuem metabólitos secundários, saponinas e alcalóides no jambú e alcalóides e antraquinonas no coentro e na chicória. Os extratos hexânico e etanólico de chicória, acetato de etila de coentro e hexânico, acetato de etila e etanol e chicória possui propriedades inibitórias frente a bactéria $S$. aureus. Esses achados contribuem para um futuro emprego das espécies vegetais como fitoterápico em tratamento preventivo ou alternativo contra infecções bacterianas.

\section{Agradecimentos}

Ao Programa de iniciação científica Centro Universitário da Amazônia - UNAMA/SANTARÉM 


\section{Referências}

Abreu, A. C. S. \& Botelho, L. L. S. (2018). Os riscos do uso de plantas medicinais durante o período gestacional: uma revisão bibliográfica. Revista Acta Toxicolol. argent, 26(3), 118-123.

Andrade, A. P. C., et al. (2019). Ação dos extratos hidroalcóolicos e aquoso da folha da goiabeira (Psidium guajava L.) no controle de Staphylococcus aureus ATTCC 27922, Escherichia coli ATTCC 25922 e Listeria monocytogenes SCOTTA. Revista segurança alimentar e nutricional. 26:1-7 https://doi.org/10.20396/san.v26i0.8655619

Andreo, D. \& Jorge, N. (2006). Antioxidantes naturais: técnicas de extração. Boletim do Centro de Pesquisa de Processamento de Alimentos, 24(2): 319-336. http://dx.doi.org/10.5380/cep.v24i2.7489

Antunes, J. C. L., et al. (2015). Rendimento e Avaliação Antimicrobiana de Extratos de Três Espécies de Solanaceae no norte mineiro. Revista Bionorte, 4(1):26-34

Araújo, E. R. D., et al. (2015). Avaliação do potencial antimicrobiano de extrato hidroalcóolico e aquoso da espécie Anadenanthera colubrina frente a bactérias gram negativa e gram positiva. Revista Biota Amazônia, 5(3): 66-71. http://dx.doi.org/10.18561/2179-5746/biotaamazonia.v5n3p66-71

Barros A. C. V., et al. (2018). Prospecção fitoquímica do extrato vegetal de Piper tuberculatum JACQ. (Piperaceae) e seu potencial antimicrobiano. $C \& D$ Revista ciência e desenvolvimento, 11(2): 316-334. 10.19177/rgsa.v8e32019550-565

Batista, I. C. A. \& Boari, A. J. \& Quadros, A. F. F. (2016). Detecção molecular de Alternaria sp. em Chicória-do-pará (Eryngium foetidum L.). In: Congresso Brasileiro De Fitopatologia, 49, p.1 Maceió. Maceió: Embrapa Amazônia Oriental.

Beserra, F. P., et al. (2014). Jatropha curcas L. (Euphorbiáceae) como novo bioinseticida: análise fitoquímica preliminar e atividade larvivida contra Aedes aegypti (Diptera: Culicidae). Revista Amazônia Science \& health, 2(3): 17-25.

Borges, L. S. \& Guerrero, R. G. \& Lima, G. P. P. (2013). Produtividade e acúmulo de nutrientes em plantas de jambu, sob adubação orgânica e mineral. Semina: Ciências Agrária, 34(1):83-94

Brandão, M. G. (2017). Importância dos registros históricos na investigação e utilização de produtos naturais. In: Simões, C.M. O; Schenkel, E. P; Mello, J.C. P; Mentz, L. A; Petrovick, P.R. Farmacognosia do produto natural ao medicamento. ARTMED EDITORA LTDA, cap. 4, $29-38$.

Cano, F. C. S., (2021). Alimentação brasileira: das especificidades regionais à perda da identidade cultural. Diversitas Journal, 6(1), 881-899. https://doi.org/10.17648/diversitas-journal-v6i1-1583

Cardozo, A. G. L., et al. (2021). Yerba mate (Ilex paraguariensis A. St. - hil.): a comprehensive review on chemical composition, health benefits and recent advances. Research, Society and Development, 10(11), e590101120036. 10.33448/rsd-v10i11.20036

Carrera, G. C., et al. (2014). Testes fitoquímicos em extratos foliares de Oeceoclades maculata Lindl. (Orchidaceae). Revista Brasileira de Plantas Medicianais, 16(4): 938-944. https://doi.org/10.1590/1983-084X/12_174

Carvalho, A. F., et al. (2014). Avaliação da atividade antibacteriana de extratos etanólico e de ciclohexano a partir das flores de camomila (Matricaria chamomilla L). Revista Brasileira de Plantas Medicinais, 16(3):521-526. https://doi.org/10.1590/1983-084X/12_159

Corrêa, A. A. S. \& Quinzani, S. S. P. \& Capovilla V. M. (2016). A Pluralidade Gastronômica da Região Amazônia: sabores acreanos, paraenses e do Alto Rio Negro. Revista Hospitalidade, 13(2):248-271 https://doi.org/10.21714/2179-9164.2020.v17n1.007

Favoreto, R. \& Gilbert, B. (2010). Acmella oleracea (L.) R. K. Jansen (Asteraceae) - Jambu. Revista Fitos, 5(1): 83-91.

Félix-Silva J., et al. (2012). Identificação botânica e química de espécies vegetais de uso popular no Rio Grande do Norte, Brasil. Revista Brasileira de Plantas Medicinas, 14(3):548-555. https://doi.org/10.1590/S1516-05722012000300018

Fernandes, B. F., et al. (2019). Estudo etnofarmacológico das plantas medicinais com presença de saponinas e sua importância medicinal. Revista da Saúde da AJES, 5(9):16-22.

Franzen, F. L., et al. (2018). Teor e rendimento de extratos de flores obtidos por diferentes métodos e períodos de extração. Acta Iguazu, 7(1): 9-21. https://doi.org/10.48075/actaiguaz.v7i1.16765

Frazão, G. C. C., et al. (2013). Qualidade microbiológica de chicória in natura e minimamente processada.in: $5^{\mathrm{a}}$ jornada científica e tecnológica e $2^{\text {o }}$ simpósio de pós-graduação do IFSULDEMINAS, 1-6, Inconfidentes, Minas Gerais.

Gobbo-Neto, L. \& Lopes, N. P. (2007). Plantas medicinais: fatores de influência no conteúdo de metabólitos secundários. Revista Quimica Nova, 30(2):374381. https://doi.org/10.1590/S0100-40422007000200026

Junior, C. L. S. \& Freire, M. G. M \& Moreira, A. S. N. (2014). Atividade antimicrobiana de extratos vegetais sobre o desenvolvimento de Acidovorax avenae subsp citrulli. Revista Verde de Agroecologia e Desenvolvimento Sustentável, 9(3):157-161.

Kumar, R. S., et al. (2014). Preliminary studies on phytochemicals and antimicrobial activity of solvente extracts of Coriandrum sativum L. roots (Coriander). Journal of Pharmacognosy and Phytochemistry, 2(8):74-78.

Leite, R.F. (2016). Concentração inibitória mínima de extratos brutos produzidos por actinobacterias para agentes causadores de mastite bovina. 97p. Dissertação (Mestrado-Área de nutrição e produção animal) - Departamento de nutrição e produção animal, Universidade Federal de São Paulo, Pirassununga, São Paulo. 
Research, Society and Development, v. 11, n. 2, e52011226047, 2022

(CC BY 4.0) | ISSN 2525-3409 | DOI: http://dx.doi.org/10.33448/rsd-v11i2.26047

Lôbo, K. M. S., et al. (2010). Avaliação da atividade antibacteriana e prospecção fitoquímica de Solanum paniculatum Lam. e Operculina hamiltonii (G. Don) D. F. Austin \& Staples, do semi-árido paraibano. Revista Brasileira de Plantas Medicinais, 12(2): 227-233. https://doi.org/10.1590/S151605722010000200016

Magalhães L. S., et al. (2015). Avaliação da atividade antibacteriana do extrato de Caesalpinia ferrea Martius e desenvolvimento de uma formulação fitocosmética. Revista Científica da Faminas, 11(1):21-31 ISSN 1807-6912.

Marques, J. P. \& Lopes, G. C. (2015). Alcaloides como agentes antitumorais: Considerações químicas e biológicas. UNINGÁ Review Journal, $24(1): 56-61$.

Paul, J. H. \& Seaforth, C. E. \& Tikasingh, T. (2011). Eryngium foetidum L.:a review. Fitoterapia, 82(3):302-308. 10.1016/j.fitote.2010.11.010

Pereira, M. A. S., et al. (2000). Seasonal variation in coumarin content of Mikania glomerata. Journal of Herbs, Spices e Medicinal Plants, 7(2):1-10. https://doi.org/10.1300/J044v07n02_01

Pereira, M. F. S., et al. (2011). Qualidade fisiológica de sementes de coentro [Coriandrum sativum(L.)]. Revista Brasileira de Plantas Medicinais, 13(especial):518-522. https://doi.org/10.1590/S1516-05722011000500002

Rodrigues, L. S. \& Silva, A. R. A. \& Macêdo, A. A. M. (2017). Noni (Morinda citrifolia Linn): Determinação fitoquímica e potencial antioxidante pelo método DPPH. Conexões ciência e tecnologia, 11(4): 47-57. https://doi.org/10.21439/conexoes.v11i4.921

Rodrigues, T. L. M., et al. (2021). Physiological performance and chemical compositions of the Eryngium foetidum L. (Apiaceae) essential oil cultivated with different fertilizer sources. Natural Product Research, 35(23), 5544-5548. https://doi.org/10.1080/14786419.2020.1795653

Santos, J.C. et al. (2016). Atividade antimicrobiana de extratos hidroalcoólicos de plantas frente à Staphylococcus aureus isolados de bovinos com mastite. Revista Científica Univiçosa. 8(1), 123-129.

Silva J. S., et al. (2017). Comportamento de preços de hortaliças folhosas na região metropolitana de Belém. Enciclopédia Biosfera, 14(26):206-213. 10.18677/EnciBio_2017B18

Silva, N. L. A. \& Miranda, F. A. A. \& Conceição, G. M. (2010). Triagem Fitoquímica de Plantas de Cerrado, da Área de Proteção Ambiental Municipal do Inhamum, Caxias, Maranhão. Scientia plena, 6(2): 25-40.

Simonetti, E. (2015). Avaliação da atividade antimicrobiana de extratos de Eugenia anomala e Psidium saluture (Myrtaceae) frente à Eschericha coli e Listeria monocytogenes. 101p. Lajeado. Dissertação (Mestrado - Área de biotecnologia). Centro Universitário UNIVATES programa de pós-graduação STRICTU SENSU.

Sousa, I. J. O., et al. (2018). Estudo fitoquímico, avaliação da capacidade hemolítica e antimicrobiana de um extrato bruto da casca do caule de Ziziphus joazeiro Mart. (Rhamnaceae). Journal of Biology \& Pharmacy and Agricultural Management, 14(4):208-225.

Souza, A. P. O., et al. (2015). Atividade antimicrobiana dos sumos de alecrim, aroeira, guiné e mastruz sobre Staphylococcus aureus e Escherichia coli. Scientia plena, 11(7):1-9.

Stehmann, J. R. \& Sobral, M., (2017). Biodiversidade no Brasil. Simões, CMO, 1-10. 